\title{
Nanofertilisers. An outlook of crop nutrition in the fourth agricultural revolution
}

\author{
Luca Marchiol
}

Department of Agri-Food, Animal and Environmental Sciences, University of Udine, Italy

\begin{abstract}
With the world's population expected to exceed nine billion by 2050 , scientists are working to develop new ways to meet rising global demand for food, energy and water without increasing the strain on natural resources. Organisations including the World Bank and the U.N. Food and Agriculture Organisation are calling for more innovation to address the challenges of the agri-food sector. The wide use of synthetic fertilisers has led to negative impacts on the environment and on farmer economies. Innovative cost-effective and eco-compatible strategies are needed in the modern and in the future precision agriculture. This goal could be achieved by reducing the amount of fertilisers applied on crops, in particular, by finding new techniques to distribute the necessary plant nutrients taking into account water and land scarcity, climate change and ecosystems. Nanotechnology is one of six keyenabling technologies that contribute to smart, sustainable competitiveness and inclusive growth in many sectors. It is expected
\end{abstract}

Correspondence: Luca Marchiol, Department of Agri-Food, Animal and Environmental Sciences, University of Udine, via delle Scienze 206, 33100 Udine, Italy.

Tel.: +39.0432.558611 - Fax: +39.0432 .558603 .

E-mail: marchiol@uniud.it

Key words: Nanotechnologies; nanofertilisers; nutrient use efficiency.

Acknowledgements: the author is grateful to Regione Friuli Venezia Giulia, General Directorate of Environment, for its financial support to the project Nanomateriali 2017-2020.

Conflict of interests: the author declares no potential conflict of interests.

Conference presentation: part of this paper was presented at the $2^{\text {nd }}$ workshop AgriNanoTechniques: Nanomaterials for products and applications in agriculture, NanoInnovation 2018 (Rome, September 12, 2018).

Dedication: this paper is dedicated to the memory of Professor Giuseppe Zerbi.

Received for publication: 25 November 2018.

Revision received: 8 May 2019.

Accepted for publication: 10 May 2019.

(C) Copyright: the Author(s), 2019

Licensee PAGEPress, Italy

Italian Journal of Agronomy 2019; 14:1367

doi:10.4081/ija.2019.1367

This article is distributed under the terms of the Creative Commons Attribution Noncommercial License (by-nc 4.0) which permits any noncommercial use, distribution, and reproduction in any medium, provided the original author(s) and source are credited. that properly designed nanostructures will allow controlled release of nutrients to synchronise the release with crops nutritional needs. However, the deliberate introduction of nano-sized materials in agricultural activities raises concerns over the possible implications for human health and the environment. The introduction of nanotechnologies in agriculture still need deepen basic and applied knowledge, however several promising results were achieved, so far. The paper presents an overview on the most recent insights and the perspectives of applied research.

\section{Introduction}

The current worldwide population of 7.6 billion is expected to reach 8.6 billion in 2030, 9.8 billion in 2050 and 11.2 billion in 2100 (UN DESA, 2017). Among the great challenges of the next century there will be the imperative to ensure an adequate amount of food and water for the world's population. All this must take place with the utmost consistency as possible with regard to the principles of sustainability. So, without increasing the current pressure on natural resources, without consuming other soil, not forgetting the scenarios of global climate change (Lobell et al., 2011). Given the magnitude of this challenge and with limited land and water resources, food security can be met only by increasing productivity and a more efficient use of productive factors (Premanandh, 2011). For all of these reasons, scientific research is called to provide the knowledge for new disruptive technologies.

In the history of mankind, the processes of technological change and population growth are the motor of social change (Johnson and Earle, 1987). One good example is Agriculture. The evolution of man is intimately linked to primary production. About 12,000 years BCA, during the Neolithic Age a climatic crisis - probably an extended drought - stimulated the birth and the technical evolution of the agricultural practice. That is known as the First Agricultural Revolution and allowed the transition from hunter-gatherers to farmers, the realisation of stable settlements, improvement of diet quality, and creation of new social roles and relationships (Zohary et al., 2012).

Making a great leap forward in time, at the turn of the late 1700 s and early 1800 s we recognise a Second Agricultural Revolution. It corresponds to the introduction of inventions like steam engines and seed drills, as well as new agronomic practices. This increased the efficiency of farmers' work and improved the productivity of the lands (Taylor, 1988). The Third Agricultural Revolution, better known as Green Revolution began in the 1930. The introduction of varieties of wheat, rice, corn, etc. high genetic potential associated with the use of significant inputs of fertilisers, water and other chemicals, has allowed a significant increase in world agricultural production (Den Herder et al., 2010). Today the positive trend has undergone a significant slowdown, while the impact of agricultural activities on the environment has grown in a worrying manner (Pingali, 2012).

Currently we are observing the birth of the Fourth Agricultural 
Revolution. The future farm management approach will be precision agriculture (Sung, 2018). The fundamental goal of this evolution is to couple crop yield maximisation with minimisation of productive factors (i.e. fertilisers, plant protection products). To achieve this result precision farming uses advanced tools and technologies such as computers, GPS and remote sensing devices to monitoring environmental parameters. Nanotechnology is considered one of the most important drivers of precision farming since the properties of nanomaterials will enable the development of more efficient strategies for crop management (Duhan et al., 2017). According to Chen et al. (2011), Gogos et al. (2012), Mura et al. (2013), Mukhopadhyay (2014), Prasad et al. (2014), Singh et al. (2015), Manjunatha et al. (2016) Raliya et al. (2018) and Kim et al. (2018), the potential of nanotechnology to support precision agriculture mainly concern plant protection products, plant growth promoters and biosensors. This paper aims to highlight the most recent advances in crop nano-nutrition and the future research perspectives.

\section{Nanotechnology and Agriculture}

There's plenty of room at the bottom was the take-to-home message of a talk held by Richard Feynman in late December 1959 at the Annual Meeting of the American Physical Society, CalTech Pasadena (Feynman, 1960). Beyond its literal meaning, nowadays this sentence is frequently used as a coded signal to introduce any discussion concerning nanotechnologies. At that time Feynman only theorised the following basic concept: The principles of physics, as far as I can see, do not speak against the possibility of manoeuvring things atom by atom. It is not an attempt to violate any laws; it is something, in principle, that can be done; but in practice, it has not been done because we are too big. The manipulation of matter at atomic level, and the birth of nanotechnologies would become reality only after 30 years.

European Union (EU) identifies nanotechnology as Key Enabling Technology for the contribution to sustainable competitiveness and growth in several fields of industrial application underpinning the shift to a greener economy. EU defines engineered nanomaterial (ENMs) any intentionally produced material that has one or more dimensions of the order of $100 \mathrm{~nm}$ or less or that is composed of discrete functional parts, either internally or at the surface, many of which have one or more dimensions of the order of $100 \mathrm{~nm}$ or less, including structures, agglomerates or aggregates, which may have a size above the order of $100 \mathrm{~nm}$ but retain properties that are characteristic of the nanoscale (EU, 2015).

Owing to its wide range of uses, the global nanotechnology market is expected to grow at an annual rate of around 17\% during the forecasted period of 2018-2024 (Research and Markets, 2018). The EU nanomaterials market generated revenue of more than USD 2.5 billion in 2015 and is expected to reach USD 9.1 billion by 2022 (Inshakova and Inshakov, 2017). At present, the healthcare industry is one of the largest sectors whereas significant developments are also being done in other sectors like electronics, energy and agriculture. However, as compared to other fields of nanotechnology application agriculture is still a marginal sector.

A publication analysis in nanotechnology research outputs was carried out on Scopus to evaluate the growth of literature outputs in that area of knowledge. The queries Nanotechnology and Nanotechnology AND Agriculture were launched (accessed date: October 2, 2018). No data output filters on document type were imposed. It is found that a total output of worldwide scientific communications in the field of nanotechnology is 146,720 during the period between 1991 and 2018 while we have only 771 outputs in nanotechnology and agriculture in the period 1999-2018 (Figure 1). At the moment the impact of the agriculture-oriented outputs is only $0.52 \%$ compared to the total. This very low value certainly depends on the fact that studies on nano applications in the primary sector started with a delay of about 10 years compared to other research areas. This delay is indirectly confirmed in Table 1 where are compared the type of research products in the two scenarios. Considering the most aggregated data (Nanotechnology), the research papers associated with the congress papers represent almost $82.8 \%$ of the total research products, and the review papers are less than $10 \%$ (Table 1). In the case of the agricultural sector, the production of original data (research paper + congress papers) represents $54.5 \%$ of the total, whereas over a quarter of the published works are review papers (25.8\%) (Table 1). This represents a structural difference between the research work in the nanotechnology sector as a whole and those specifically oriented to the agricultural sector. Further considerations on this point will be devel-

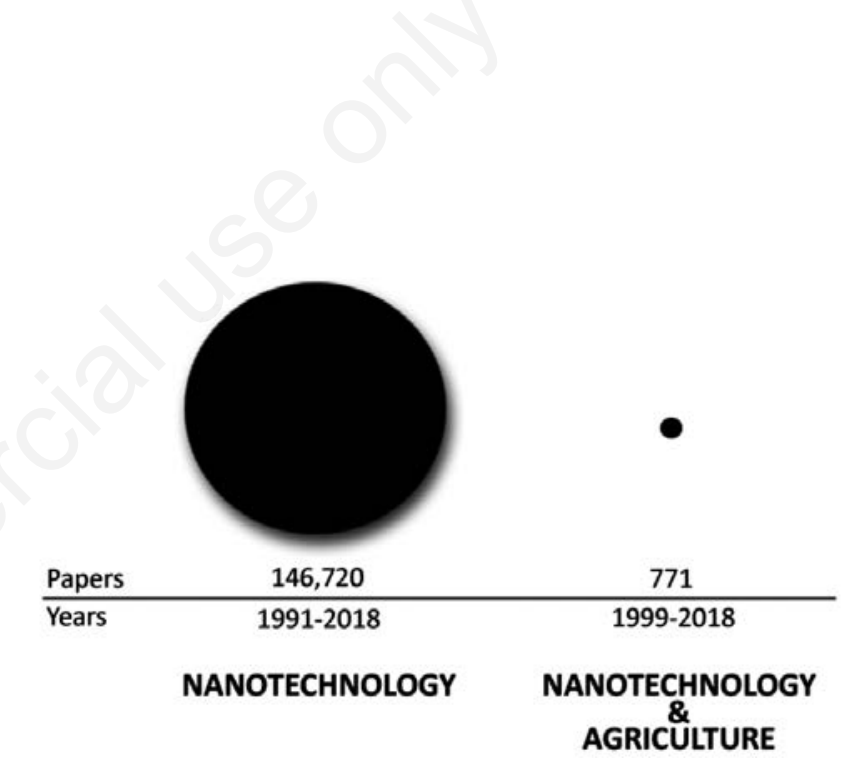

Figure 1. Statistics of the number of scientific products per year retrieved in Scopus, searching for Nanotechnology and Nanotechnology AND Agriculture, respectively.

Table 1. Different types of published documents retrieved in Scopus, searching for Nanotechnology and Nanotechnology AND Agriculture, respectively. The value in brackets is the percentage compared to the total.

\begin{tabular}{lcc}
$\begin{array}{l}\text { Document type } \\
\text { Article }\end{array}$ & Nanotechnology & $\begin{array}{c}\text { Nanotechnology } \\
\text { AND Agriculture }\end{array}$ \\
Review & $79,051(54.3 \%)$ & $300(39.2 \%)$ \\
Conference paper & $13,928(9.6 \%)$ & $197(25.8 \%)$ \\
Book chapter & $41,569(28.5 \%)$ & $117(15.3 \%)$ \\
\hline Book & $4152(2.9 \%)$ & $97(12.7 \%)$ \\
Editorial & $1097(0.8 \%)$ & $19(2.5 \%)$ \\
\hline Note & $2296(1.6 \%)$ & $17(2.2 \%)$ \\
Short survey & $1270(0.9 \%)$ & $9(1.2 \%)$ \\
\hline Confere rew & $1458(1.0 \%)$ & $9(1.2 \%)$
\end{tabular}


oped later, focusing on the theme of nanofertilisers.

The literature analysis was then refined searching for the queries Nanotechnology AND Agriculture AND Pesticides, and Nanotechnology AND Agriculture AND fertilisers. In Figure 2 the new Scopus outputs are reported as broken lines, maintaining for reference also the general output Nanotechnology AND Agriculture. The trend of total outputs is exponentially growing since 2008. Until 2010, most of the work concerns the applications of nanotechnology in the technology sector, that is, food transformation and packaging. So, only a few years ago scientists began work on field applications, namely on the use of nanoproducts for plant protection products and crop fertilisation.

After examining the quantitative evolution of the works in the period 1999-2018, let's see in which countries they have been financed and carried out (Figure 3). India and United States share the research leadership, having published together about $56 \%$ of products $(29.6 \%$ and $26.5 \%$, respectively). China possesses the third rank (10.1\%), whereas EU countries contribute with $12.4 \%$ of publications.

\section{Nanomaterials and crop nutrition}

Crop fertilisation has been essential to feed world's population. Long-term field studies demonstrated that $30 \%$ to $50 \%$ of crop yield is attributable to fertiliser inputs in temperate regions and their contribution is much higher in tropical climates (Stewart and Roberts, 2012). In other words, we can state that it is practically impossible to obtain adequate crop yields without fertilisation since very few soils are naturally fertile and able to provide all nutrient elements requested by crops.

Green-revolution agriculture has benefited from the introduction of major innovations that have made it possible to dramatically increase crop yields. So far, the response to the demand for increased crop yield production was simply that of increasing the extension of agricultural lands, and the input doses (e.g. energy, fertilisers, pesticides and water) (Pisante et al., 2012). Consider, for example that the amount of nitrogen and phosphorus fertilisers increased about 20-fold and 7-fold, respectively in the years 19502000 (Bouwman et al., 2013). Unfortunately, this model of agriculture is unsustainable and will not guarantee food safety. This is even more worrying if we consider the projections on the demographic increase expected by the end of this century.

In general terms, the result of plant's ability to explore soil for nutrients, combined with the soil capability to supply nutrients to plant roots is evaluated by using the Nutrient Use Efficiency (NUE). According to López-Arredondo et al. (2017): NUE is defined in terms of yield and input, and can be described as the relationship between the amount of nutrients acquired by plants and the resulting production of biomass (fruits, forage, and grains). Experimental data demonstrated that in all agroecosystems around $40-70 \%$ of nitrogen, $80-90 \%$ of phosphorus and 50 $90 \%$ of potassium supplied with fertilisers are unable to be takenup by plant roots due to physical and chemical soil properties, leaching, gaseous losses and fertiliser characteristics (Trenkel, 2010; Solanki et al., 2015; Baligar et al., 2015).

The unique physicochemical properties of nanomaterials, i.e., catalytic reactivity, high surface area, size and shape, have the potential to open new paradigms and to introduce new strategies in agriculture (De Rosa et al., 2010). The development and utilisation of the potential of nanotechnologies in crop fertilisation is a new frontier in fertiliser research.

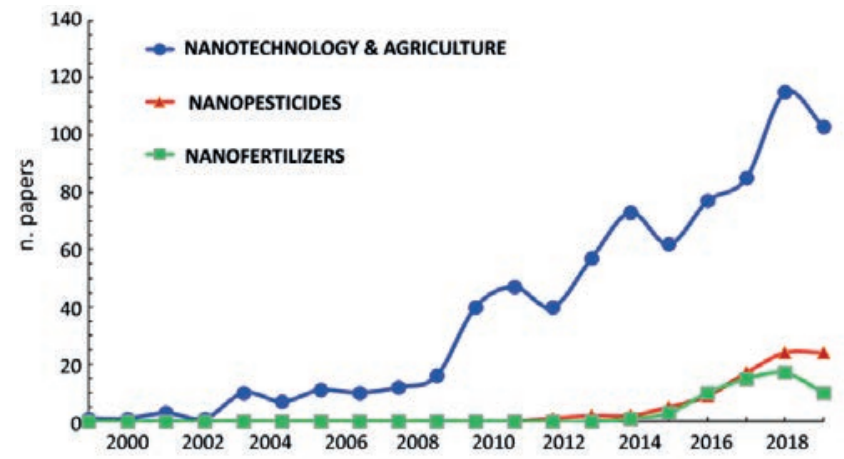

Figure 2. Number of scientific outputs per year (1999-2018) for the queries: Nanotechnology AND Agriculture, Nanotechnology AND Agriculture AND Pesticides, and Nanotechnology AND Agriculture AND fertilisers.

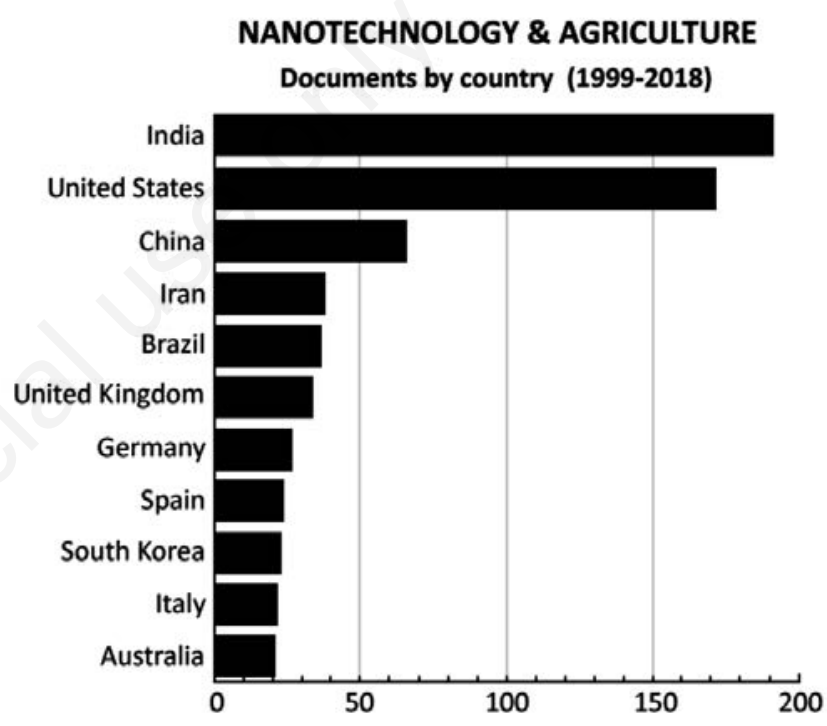

Figure 3. Country distribution of scientific products, with reference to Figure 2 (countries having less than 20 publications not showed).

\section{Nanofertiliser means smart functions}

Conventional fertilisers have low nutrient uptake efficiencies and are often associated with high losses to the environment and consequent negative consequences. On the other hand, the keypoint of crop fertilisation is to avoid nutrient losses and synchronise the nutrient availability with its uptake by crops (Gogos et al., 2012; Duhan et al., 2017; Kim et al., 2018). According to Yuhandhar et al. (2015) smart materials are defined as materials that sense and react changing their shape or behaviour through external influences, including pressure, temperature, moisture, $\mathrm{pH}$, and electric and magnetic fields. Transferring this concept in the field of fertilisers it is expected that the future design of nanofertilisers will strongly influence the nutrient release allowing a dramatic reduction of nutrient losses. This can be achieved in two ways: i) improving the current fertilisers with nano-properties; or ii) designing new types of fertilisers (Pereira et al., 2015).

The first option concerns the adoption of advanced technologies in order to produce nanosized fertiliser formulations. The sec- 
ond option, much more ambitious, is projected into the future. It envisages that properly designed nanocapsules containing nutrients will be programmed to release them when stimulated by environmental factors or man-induced pulses (Figure 4A). According to Manjunatha et al. (2016), some possible control mechanisms are the following: i) Specific release: the nutrient release occurs through a recognition mechanism between a receptor (molecule or functional group) bound to the shell and a target molecule; ii) Moisture release: the shell breaks down and releases nutrients in the presence of water; iii) $\mathrm{pH}$ release: the shell breaks up only in specific alkaline/acid environment (e.g., within plant tissues or inside a cell); iv) Magnetic or ultrasonic pulses: the shell opens in response to a magnetic or ultrasonic pulse emitted by a man-controlled system.

Another strategy, equally based on the principle of smart materials, consider the design and synthesis of structures formed by nanocapsules containing the plant nutrients, incorporated within a matrix of clay and organic polymers acting as carrier (Figure 4B). The properties of the nanostructure allow a controlled release of nutrients as function of time or after interactions with the environment (Corradini et al., 2010; Aouada and de Moura, 2015; Ramos Campos et al., 2015; Morales-Díaz et al., 2017).

\section{Nanofertilisers versus conventional fertilisers}

As previously reported, the intensive use of fertilisers associated with the poor NUE is causing environmental problems and a loss of financial resources. Moreover, apart from nitrogen that is synthesized by Haber-Bosh process, phosphorus and potassium cannot be made or substituted, and are mined and depleted. So a future criticality is foreseen in the supply of raw material to fertiliser industry (Suppan, 2017).

The low NUE is basically due to a lack of synchronisation between the nutrient release by fertiliser and the nutrient demand during plant growth. Thus, the current challenge for crop management is to optimise the use of fertilisers to fulfil the crop nutrient requirements and to minimise the risk of environmental pollution. It is expected that properly designed nanostructures will allow controlled release of nutrients (Sasson et al., 2007; Cui et al., 2010; Solanki et al., 2015; Inácio Pereira et al., 2015). This implies a better control in release rate and release pattern of nutrients. This in turn will allow us to extend effective duration of nutrient supply of fertilisers into soil with the objective to meet the actual nutritional needs of crops (Liu and Lal, 2015). Another point is related with low solubility of mineral micronutrients (Monreal et al., 2016).
Always conventional micronutrient fertilisers provide elements having large particle size and low solubility. This makes micronutrient less bioavailable to plants. Micronutrient nanofertilisers may improve solubility and dispersion (and loss) of insoluble nutrients in soil, reducing soil absorption and fixation, and increase the bioavailability of elements. Overall, then nanofertilisers might increase the NUE and uptake ratio of the soil nutrients in crop biomass and save fertiliser resource.

\section{Types of nanofertilisers}

The term nanofertiliser refers to a structure in the dimension of 1-100 $\mathrm{nm}$ that delivers macro/micronutrients to crops. In addition, this term should also be extended to indicate bulk materials used together with nanoscale structures to construct new products (Raliya et al., 2017). The fact that we have a double interpretation of the word nanofertiliser implies that for an appropriate classifi-

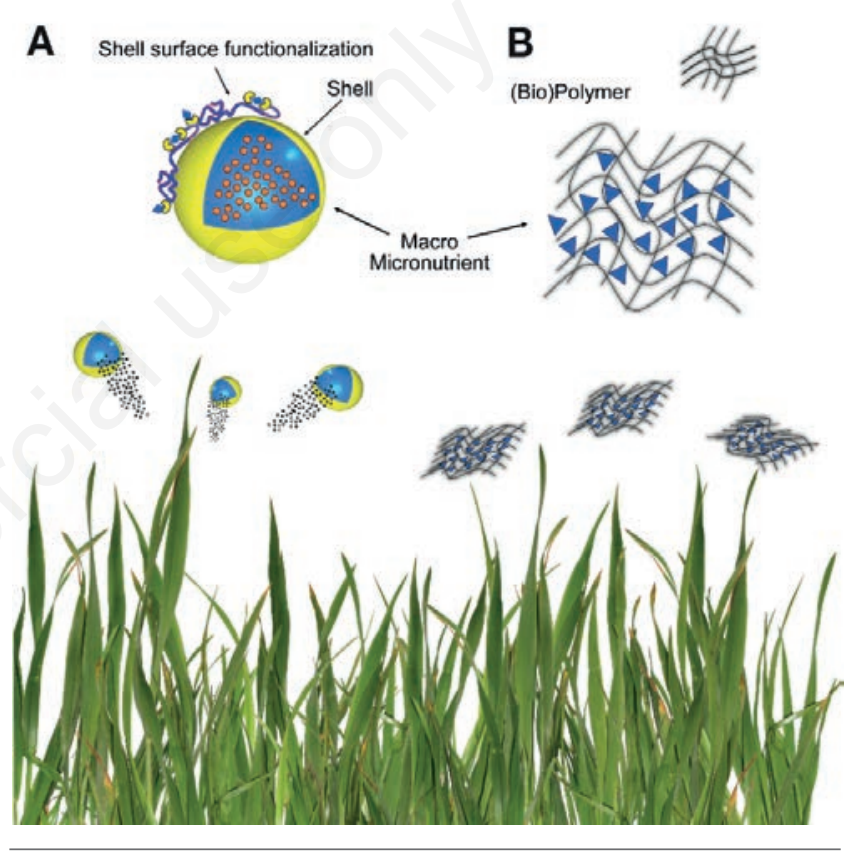

Figure 4. Models of nanofertiliser. A) Nanocapsule containing macro/microelements with shell conjugates molecules acting as activators of shell opening; B) Biopolymeric structure containing macro/microelements.

Table 2. Nanofertilisers classified with respect of their functions and composition.

\begin{tabular}{|c|c|c|c|c|}
\hline Nanomaterials & Macronutrient fertiliser & Micronutrient fertiliser & $\begin{array}{l}\text { Function } \\
\text { NM-enhanced fertiliser }\end{array}$ & Plant growth stimulator NM \\
\hline Metallic & & $\begin{array}{l}\text { Copper } \\
\text { Iron } \\
\text { Manganese } \\
\text { Molybdenum } \\
\text { Zinc }\end{array}$ & & \\
\hline Non polymeric & $\begin{array}{l}\text { Calcium } \\
\text { Magnesium } \\
\text { Calcium-phosphate }\end{array}$ & & Nutrient loaded zeolites & $\begin{array}{l}\text { Cerium } \\
\text { Titanium }\end{array}$ \\
\hline Polymeric & $\begin{array}{l}\text { Nitrogen } \\
\text { Potassium }\end{array}$ & & Nano chitosan & $\begin{array}{l}\text { SWCNTs } \\
\text { MWCNTs } \\
\text { Graphene } \\
\text { Fullerene }\end{array}$ \\
\hline
\end{tabular}


cation of nanomaterials we must take into account both the nutritional role towards the plants and their chemical structure, which in turn is responsible for the fate of the materials and their interactions with the environment. Based on structural properties, the nanomaterials may be classified as nanocrystallines and nanostructures. The nanostructures may be polymeric (dendrimer, micelles, conjugates) or non-polymeric (carbon nanotubes, silica, or metallic NPs) (Poddar et al., 2018). This being so and according to Liu and Lal (2016), Table 2 reports a classification of nanofertilisers.

The research dedicated to the development of nanofertilisers is currently in progress. A series of reviews published in the last two years by Chhipa (2016), Ditta and Arshad (2016), Duhan et al. (2017), Raliya et al. (2018), and Dimpka and Bindraban (2018) provide the state of the art on this issue and the details on (nano)macrofertilisers and microfertilisers (Table 2). If these new products are an evolution of traditional fertilisers, which acquire the properties of matter at the nanoscale, what can open a new dimension in plant nutrition are the nanomaterial-enhanced fertilisers (NEF) and plant growth stimulator NMs (Table 2).

According to Liu and Lal (2016) the NEF are nanomaterials loaded with plant nutrient(s), aimed at increasing plant-uptake efficiency of the nutrient(s) and/or reducing the adverse impacts of fertiliser application, but the nanomaterials themselves do not contain or supply the targeted nutrient(s). Zeolites are a group of crystalline aluminosilicate minerals that since the 1980s are studied for applications in plant nutrition depending by the fact that their cagelike structure can be loaded with macronutrients and micronutrients, which can be slowly released (Hershey et al., 1980). Current studies consider nano-forms of nutrient loaded zeolites. Recent experimental activity by Lateef et al. (2016), Rajonee et al. (2016, 2017), Subramanian and Thirunavukkarasu (2017) and Yuvaraj and Subramanian (2018) confirmed the potential of N-loaded zeolite and PK-loaded zeolite.

Chitosan is a biocompatible and biodegradable biopolymer of glucosamine and $\mathrm{N}$-acetyl glucosamine residues, extractable from chitin, which is available from crustacean skeleton (Saharan and Pal, 2016). Chitosan based nanoparticles as compared to bulk chitosan as well as to other biopolymers such as chitin, starch, gelatin, cellulose and glucans, has a higher surface to volume ratio and surface charge (Nguyen et al., 2013). For that reason, they have been proposed for delivery of macro/micronutrients, fertilisers, phytohormones, herbicides and pesticides and plant protection products (Kumaraswamy et al., 2018).

Table 2 contain some other nanomaterials grouped as Plant Growth Stimulator-NMs. They widely differ in structure and dimensions, however even though not clear functions in plant physiology have been discovered, several experimental evidences demonstrated their potential in stimulating plant growth.

Cerium nanoparticles $\left(n \mathrm{CeO}_{2}\right)$ and titanium nanoparticles $\left(n \mathrm{TiO}_{2}\right)$ are widely used in industry (Piccinno et al., 2012). As a consequence, relevant amounts of such materials are already spreading in the environment (Dahle and Arai, 2015; Shah et al., 2017), and the Organisation for Economic Cooperation and Development include them is the list of engineered nanomaterials for immediate priority testing (OECD, 2010). Whether experimental evidence on the positive effects of $n \mathrm{CeO}_{2}$ on plant metabolism is still rather poor (Lizzi et al., 2017), multiple demonstrations have been obtained on the positive effects of $n \mathrm{TiO}_{2}$ (Mattiello et al., 2017).

A large group of carbon-based engineered nanomaterials, namely carbon nanotubes (CNTs), graphene and fullerenes can be considered as the new frontier of plant nutrition.

An overview on the effects of CNTs on plants, was recently provided by Vithanage et al. (2018). However, since the response of the plants varies according to the type of CNTs (single walled or multiple walled CNTs), more accurate information will have to be associated with the classification of carbon nanomaterials, which in turn are in a very intense development phase.

As far as graphene and fullerenes, several evidences demonstrating that exposure to such materials stimulate of seed germination and root growth were reported by Husen and Siddiqui (2014) and references therein, Zhang et al. (2015), Liu et al. (2015), Li et al. (2018), Shen et al. (2018). However, the mechanism by which such nanostructures promote plant growth, remains still unclear. On the other hand, toxic effects and plant growth inhibition, induced by the same materials were verified, as well (Anjum et al., 2014; Hu et al., 2014a; Chung et al., 2015; Zaytseva and Neumass, 2016).

This first report on the agronomic performance of graphenebased slow-release $\mathrm{Zn}$ and $\mathrm{Cu}$ fertiliser was provided by Kabiri et al. (2017). Graphene has a high surface area and high density of oxygen binding sites on their surface and edge. These properties are responsible for binding the nutrients allowing a slower release compared to conventional fertilisers. Other recent papers are exploring more extensively the potential of graphene in the development of smart fertilisers (Andelkovic et al., 2018; Kabiri et al., 2018).

\section{Acquired knowledge and research gaps}

The literature reports promising demonstrations on the potential of nanomaterials in crop nutrition. However, it must be made quite clear that research on nanofertilisers and plant growth stimulator NMs is still at the embryonic stage. Then, research has the responsibility to bridging the gap between the extremely appealing prospects of nanofertilisers and the current knowledge.

Furthermore, looking towards a future application of these materials, though not discussed here, other non-trivial aspects exist, such as the technical and economic scalability of production processes and the aspects related to the social acceptance of nanotechnologies.

Based on available literature, recently Kah et al. (2018) published on Nature Nanotechnology the first ever meta-analysis, which evaluate the potential of nanopesticides and nanofertilisers against their conventional analogues. As we have seen in Table 2 the number of published studies is quite low. However, this is not the problem, but rather the fact that they are very heterogeneous, so it is quite difficult to generalise the conclusions. In addition, the following criticisms and uncertainties should be highlighted.

\section{Wide variety of experimental designs}

In scientific literature, there is a marked predominance of works carried out in controlled conditions. Actually, to be precise, there is no comprehensive study carried out under field conditions, so far.

\section{Nutrient supply method}

In the studies considered in the meta-analysis by Kah et al. (2018), nanofertilisers were supplied either by spraying the plant leaves with a solution, or applied to soil in solid formulation. That had different consequences on the plant response, as well as on the environmental fate of nanomaterial.

\section{Nutrient form comparison}

While it is certainly important to study different methods of 
Table 3. Efficacy of nanofertilisers: practical issues (Kah et al., 2018).

\begin{tabular}{lll}
\hline Application & Losses & Plant-soil system \\
Stable suspension & Reduced photolysis & Controlled release \\
Homogeneous coverage & Transport to non-target area & Improved uptake \\
\hline More precise target area & Target delivery & \\
\hline
\end{tabular}

administration of nanofertilisers, we do not yet have a thorough knowledge of the behaviour of these materials, and therefore it is likely that the results cannot be interpreted correctly. Treating this specific aspect Kah et al. (2018) strongly recommend to organise experiments in which three different sources of nutrients are compared: the nano form, the bulk form (conventional fertiliser) and the active (ionic) nutrient form. In this way it should be possible to observe both the plant responses due to the nanoscale, and due to the element bioavailability. That approach is fundamental to elucidate the mechanisms by which nanoformulations may change the behaviour of the active ingredient. Actually, the vast majority of studies the nanofertilisers were compared only to their (bulk) conventional form.

\section{Environmental footprint of nanofertilisers}

Kah et al. (2018) did not found a single study regarding the environmental footprint of nanofertilisers compared with conventional formulations, including, for example, energy costs or water use during the industrial process.

The concluding remarks of the meta-analysis provide encouraging indications for nanofertilisers. In fact, it is stated that: Nanofertilisers may increase crop production by some additional 20 to $30 \%$ compared with conventional fertilisers. Achieving similar levels of crop protection and nutrition while reducing the use of agrochemicals by 20-30\% could significantly mitigate environmental contamination. However, at the same time, it was underlined that there is a lot of experimental work to be developed to fill several gaps in the current knowledge. So, in which directions should research efforts be directed?

In general terms, significant improvements are needed in the knowledge on three major topics: i) application methods, ii) reduction of product losses and iii) relationships/interactions with the soil-plant system. Table 3 shows more detailed aspects linked to the major topics. Shortly afterwards the publication of the paper just mentioned, Pourzahedi et al. (2018) presented some thoughts pertaining to the life cycle assessment (LCA) for evaluating environmental trade-offs of nano-enabled agrochemical applications. The main issue is that at present we have only a limited availability of specific data to model life cycle material flow - from raw material use to emissions - for NMs application in agriculture. To gather the necessary information in the near future, the following research themes will need to be explored: i) field-scale experiments that track ENM/resource flows would allow for a more comprehensive data inventory; ii) behaviour, persistence and fate of NMs in agricultural soil; iii) modelling sorption of NMs to soil, their transformations, bioavailability and interaction with soil biomass.

For all the above reasons, although there is a general agreement on the prospects of nanofertilisers and confidence in the development of ever more efficient products, we must honestly acknowledge that the market - at least in EU and US - has not yet developed. On the other hand, the necessary system of rules and regulations that will allow to exploit all the potential of nanomate- rial's in agriculture while guaranteeing conditions of safety for workers, consumers and ecosystems is still under development (Kahn et al., 2018).

\section{Conclusions}

Since the urgent need of innovation in Agriculture in order to meet the future demand of food while protecting the environment, it is very likely that a responsible and safe application of nanotechnologies can play an important role. Among the different applications, in this paper was addressed the subject of crop nutrition. With this regard there are great expectations about the development of smart fertilisers capable of significantly improving crop nutrient use efficiency.

Taking into account the state of the art on that topic, we have a critical need of phenomenological studies to elucidate underlying mechanisms to advance innovative and sustainable design of nanofertilisers or plant growth stimulator NMs. In addition, since NMs are intended to neither affect human health nor impact the environment along their life cycle, NMs design synthesis and safety assessment should be implemented to previous studies. This means in our case that the behaviour of nanofertilisers - influenced by size, shape, surface charge and functionalisation and aggregation - should be thoroughly investigated before their release.

There is no doubt there is still much to do, however a future scenario in which nanostructures containing fertilisers, pesticides, and herbicides will support precision agriculture in a full controlled and environmental-friendly manner, is the ultimate goal of nanotechnology in agriculture. Then we might evaluate whether we will actually have entered the Fourth Agricultural Revolution.

\section{References}

Andelkovic IB, Kabiri S, Tavakkoli E, Kirby JK, McLaughlin MJ, Losic D, 2018. Graphene oxide-Fe(III) composite containing phosphate - A novel slow release fertiliser for improved agriculture management. J. Clean Prod. 185:97-104.

Aouada FA, de Moura MR, 2015. Nanotechnology applied in agriculture: Controlled release of agrochemicals. In: Rai M, Ribeiro C, Mattoso L, Duran N (Eds.), Nanotechnologies in Food and Agriculture. Springer, Cham, pp 103-118.

Chen H, Yadab R, 2011. Nanotechnologies in agriculture: New tools for sustainable development. Trends Food Sci. Technol. 11:585-94.

Chhipa H, 2016. Nanofertilisers and nanopesticides for agriculture. Env. Chem. Lett. 1:15-22.

Corradini E, de Moura MR, Mattoso LHC, 2010. A preliminary study of the incorporation of NPK fertiliser into chitosan nanoparticles. eXPRESS Polymer Letters. 8:509-15. 
Cui HX, Sun CJ, Liu Q, Jiang J, Gu W, 2010. Applications of nanotechnology in agrochemical formulation, perspectives, challenges and strategies. International Conference on Nanoagri, Sao Pedro, Brazil, June, 20-25.

Dahle JT, Arai Y, 2015. Environmental geochemistry of cerium: Applications and toxicology of cerium oxide nanoparticles. Int. J. Environ. Res. Public. Health. 2:1253-78.

Den Herder G, Van Isterdael G, Beeckman T, De Smet I, 2010. The roots of a new green revolution. Trends Plant Sci. 15:600-7.

Dimkpa CO, Bindraban PS, 2018. Nanofertilisers: New Products for the industry? J. Agric. Food Chem. 26:6462-73.

Ditta A, Arshad M, 2016. Applications and perspectives of using nanomaterials for sustainable plant nutrition. Nanotechnol. Rev. [Epub ahead of print].

Duhan JS, Kumar R, Kumar N, Kaur P, Nehra K, Duhan S, 2017. Nanotechnology: The new perspective in precision agriculture. Biotechnol. Rep. 125:11-23.

Feynman R, 1960. There's a plenty of room at the bottom. Engineering and Science. 5:22-26.

Gogos A, Knauer K, Bucheli TD, 2012. Nanomaterials in plant protection and fertilisation: Current state, foreseen applications, and research priorities. J. Agr. Food Chem. 60:9781-92.

Hershey DR, Paul JL, Carlson RM, 1980. Evaluation of potassium-enriched clinoptilolite as a potassium source for potting media. Hort. Sci. 15:87-9.

Husen A, Siddiqi KS, 2014. Carbon and fullerene nanomaterials in plant system. J. Nanobiotechnol. 12:16.

Inácio Pereira E, Soares Giroto A, Bortolin A, Yamamoto $\mathrm{CF}$, Marconcini JM, de Campos Bernardi AC, Ribeiro C, 2015. Perspectives in nanocomposites for the slow and controlled release of agrochemicals: Fertilisers and pesticides. In: Rai M, Ribeiro C, Mattoso L, Duran N (Eds). In: Nanotechnologies in food and agriculture. Springer, Switzerland, pp 241-265.

Inshakova E, Inshakov O, 2017. World market for nanomaterials: structure and trends. MATEC Web of Conferences 129:02013.

Johnson AW, Earle T, 1987. The evolution of human societies: From foraging group to agrarian state. Stanford University Press, USA.

Kabiri S, Degryse F, Tran DNH, da Silva RC, McLaughlin MJ, Losic D, 2017. Graphene oxide: A new carrier for slow release of plant micronutrients. ACS Appl. Mater. Interfaces. 49:43325-35.

Kabiri S, Baird R, Tran DNH, Andelkovic I, McLaughlin MJ, Losic D, 2018. Cogranulation of low rates of graphene and graphene oxide with macronutrient fertilisers remarkably improves their physical properties. ACS Sust. Chem. Eng. 1:1299-309.

Kah M, Kookana RS, Gogos A, Bucheli TD, 2018. A critical evaluation of nanopesticides and nanofertilisers against their conventional analogues. Nat. Nanotechnol. 8:677-84.

Kim D-Y, Kadam A, Shince S, Saratale RG, Patra J, Ghodake G, 2018. Recent developments in nanotechnology transforming the agricultural sector: a transition replete with opportunities. J. Sci. Food Agric. 98:849-64.

Kumaraswamy RV, Kumari S, Choudhary RC, Pal A, Raliya R, Biswas P, Saharan V, 2018. Engineered chitosan based nanomaterials: Bioactivities, mechanisms and perspectives in plant protection and growth. Int. J. Biol. Macromol. 113:494-506.

Lateef A, Nazir R, Jamila N, Alam S, Shahd R, Naeem Khan M, Saleem M, 2016. Synthesis and characterisation of zeolite based nano-composite: An environment friendly slow release fertiliser. Micropor. Mesopor. Mat. 232:174-83.

Li F, Sun C, Li X, Yu X, Luo C, Shen Y, Qu S, 2018. The effect of graphene oxide on adventitious root formation and growth in apple. Plant Physiol. Biochem. 129:122-9.

Lin S, Yu T, Yu Z, Hu Z, Yin D, 2018. Nanomaterials safer-bydesign: an environmental safety perspective. Adv. Mater. 30:1705691.

Liu R, Lal R, 2015. Potentials of engineered nanoparticles as fertilisers for increasing agronomic productions. Sci. Total Environ. 514:131-9.

Liu S, Wei H, Li Z, Li S, Yan H, He Y, Tian Z, 2015. Effects of graphene on germination and seedling morphology in rice. J. Nanosci. Nanotechnol. 4:2695-701.

Lizzi D, Mattiello A, Marchiol L, 2017. Impacts of cerium oxide nanoparticles $\left(\mathrm{nCeO}_{2}\right)$ on crop plants: a concentric overview. In: Tripathi DK, Ahmad P, Sharma S, Chauhan D. (Eds.). Nanomaterials in plants, algae and micro-organisms. Concepts and Controversies. Elsevier, The Netherlands, 1:311-22.

Lobell DB, Schlenker W, Costa-Roberts J, 2011. Climate trends and global crop production since 1980. Science 6042:616-20.

Manjunatha SB, Biradar DO, Aladakatti YR, 2016. Nanotechnology and its applications in agriculture: a review. J. Farm Sci. 1:1-13.

Mattiello A, Lizzi D, Marchiol L, 2017. Influence of Titanium Dioxide Nanoparticles $\left(\mathrm{nTiO}_{2}\right)$ on Crop Plants: A Systematic Overview. In: Tripathi DK, Ahmad P, Sharma S, Chauhan D. (Eds.). Nanomaterials in plants, algae and micro-organisms. Concepts and Controversies. Elsevier, The Netherlands, 1:277-96.

Monreal CM, DeRosa M, Mallubhotla SCM, Bindraban PS, Dimkpa C, 2016. Nanotechnologies for increasing the crop use efficiency of fertiliser-micronutrients. Biol. Fertil. Soils. 3:423-37.

Morales-Díaz AB, Ortega-Ortíz H, Juárez-Maldonado A, CadenasPliego G, González-Morales S, Adalberto Benavides-Mendoza A, 2017. Application of nanoelements in plant nutrition and its impact in ecosystems. Adv. Nat. Sci. Nanosci. Nanotech. 8:1-13.

Mura S, Seddaiu G, Bacchini F, Roggero PP, Greppi GF, 2013. Advances of nanotechnology in agro-environmental studies. Ital. J. Agron. 8:e18.

Mukhopadhyay SS, 2014. Nanotechnology in agriculture: prospects and constraints. Nanotech. Sci. Appl. 7:63-71.

Nguyen Van S, Dinh Minh H, Nguyen Anh D, 2013. Study on chitosan nanoparticles on biophysical characteristics and growth of Robusta coffee in green house. Biocatal. Agri. Biotechnol. 4:289-94.

Pereira EI, da Cruz CCT, Solomon A, Le A, Cavigelli MA, Ribeiro C, 2015. Novel slow-release nanocomposite nitrogen fertilisers: the impact of polymers on nanocomposite properties and function. Ind. Eng. Chem. Res. 54:3717-25.

Piccinno F, Gottschalk F, Seeger S, Nowack B, 2012. Industrial production quantities and uses of ten engineered nanomaterials in Europe and the world. J. Nanopart. Res. 14:1109.

Pingali PL, 2012. Green Revolution: Impacts, limits, and the path ahead. Proc Natl Acad Sci U S A 109:12302-8.

Poddar K., Vijayan J, Ray S, Adak T, 2018. Nanotechnology for sustainable agriculture. In: Singh RL, Mondal L (Eds.), Biotechnology for sustainable agriculture emerging approaches and strategies. Elsevier, The Netherlands, pp. 281-303.

Prasad R, Kumar V, Prasad KS, 2014. Nanotechnology in sustainable agriculture: present concerns and future aspects. Afr. J. Biotechnol. 6:705-13.

Pourzahedi L, Pandorf M, Ravikumar D, Zimmerman JB, Seager TP, Theis TL, Westerhoff P, Gilbertson LM, Lowry GV, 2018. Life cycle considerations of nano-enabled agrochemicals: are today's tools up to the task? Env. Sci. Nano. 5:1057-69. 
Prasad R, Bhattacharyya A, Nguyen QD, 2017. Nanotechnology in sustainable agriculture: Recent developments, challenges, and perspectives. Front. Microbiol. 8:1014.

Premanandh J, 2011. Factors affecting food security and contribution of modern technologies in food sustainability. J. Sci. Food. Agric. 91:2707-14.

Raliya R, Saharan V, Dimkpa C, Biswas P, 2018. Nanofertiliser for precision and sustainable agriculture: Current state and future perspectives. J. Agric. Food Chem. 26:6487-503.

Rajonee AA, Nigar F, Ahmed S, Huq SMI, 2016. Synthesis of nitrogen nano fertiliser and its efficacy. Can. J. Pure Appl. Sci. 2:3913-9.

Rajonee AA, Zaman S, Huq SMI, 2017. Preparation, characterisation and evaluation of efficacy of phosphorus and potassium incorporated nano fertiliser. Adv. Nanopart. 6:62-74.

Raliya R, Saharan V, Dimkpa C, Biswas P, 2018. Nanofertiliser for precision and sustainable agriculture: Current state and future perspectives. J. Agric. Food Chem. 26:6487-503.

Ramos Campos EV, de Oliveira JL, Fernandes Fraceto L, Singh B, 2015. Polysaccharides as safer release systems for agrochemicals. Agron. Sustain. Dev. 35:47-66.

Regulation (EU) 2015/2283 of the European Parliament and of the Council of 25 November 2015 on novel foods, amending Regulation (EU) No 1169/2011 of the European Parliament and of the Council and repealing Regulation (EC) No 258/97 of the European Parliament and of the Council and Commission Regulation (EC) No 1852/2001.

Research and Markets, 2018. Global Nanotechnology Market Outlook 2024. Industry Research Report. Available from: https://www.researchandmarkets.com/research/9d2zws/global?w=4 Accessed: 20 Sept, 2019.

Saharan V, Pal A, 2016. Chitosan based nanomaterials in plant growth and protection. Springer Briefs in Plant Sci. [Epub ahead of print].

Sasson Y, Levy-Ruso G, Toledano O, Ishaaya I, 2007. Nanosuspensions: emerging novel agrochemical formulations. In: Ishaaya I, Nauen R, Horowitz AR (Eds). Insecticides design using advanced technologies, Springer-Verlag, Berlin Heidelberg, Germany, pp. 1-39.

Servin A, Elmer W, Mukherjee A, De la Torre-Roche R, Hamdi H, White JC, Bindraban P, Dimkpa C, 2015. A review of the use of engineered nanomaterials to suppress plant disease and enhance crop yield. J. Nanopart. Res. 17:92.

Shah SNA, Shah Z, Hussain M, Khan M, 2017. Hazardous effects of titanium dioxide nanoparticles in ecosystem. Bioinorg. Chem. Appl. 4101735.

Shen S, Liu Y, Wang F, Yao G, Xie L, Xu B, 2018. Graphene oxide regulates root development and influences IAA concentration in rice. J. Plant Growth Reg. [Epub ahead of print].
Singh S, Singh BK, Yadav SM, Gupta AK, 2015. Applications of nanotechnology in agricultural and their role in disease management. Res. J. Nanosci. Nanotech. 5:1-5.

Solanki P, Bhargava A, Chhipa H, Jain N, Panwar J, 2015. Nanofertilisers and their smart delivery system. In: Rai M, Ribeiro C, Mattoso L, Duran N (Eds.) Nanotechnologies in food and agriculture. Springer, Switzerland, pp 81-101.

Subramanian KS, Thirunavukkarasu M, 2017. Nano-fertilisers and nutrient transformations in soil. In: Ghorbanpour M, Manika K, Varma A (Eds.), Nanoscience and plant-soil systems - Soil biology. Springer International Publishing, 48:305-19.

Sung J, 2018. The fourth Industrial revolution and precision agriculture. In: Hussmann S (Ed.). Automation in Agriculture. IntechOpen [Epub ahead of print].

Suppan S, 2017. Applying nanotechnology to fertiliser: rationales, research, risks and regulatory challenges. The Institute for Agriculture and Trade Policy. Available from: https://www.iatp.org/documents/applying-nanotechnologyfertiliser-rationales-research-risks-and-regulatory-challenges Accessed: 30 October 2018.

Taylor D, 1988. The Agrarian Revolution 1750-1850. In: Mastering Economic and Social History. Macmillan Master Series, Palgrave, London, UK.

Trenkel ME, 2010. Slow-and controlled-release and stabilised fertilisers: an option for enhancing nutrient use efficiency in agriculture. pp 1-162 in International Fertiliser Industry Association, Paris, France.

UNDESA (United Nations, Department of Economic and Social Affairs, Population Division), 2017. World Population Prospects: The 2017 Revision, Key Findings and Advance Tables. Working Paper No. ESA/P/WP/248.

Vithanage M, Seneviratne M, Ahmad M, Sarkar B, Ok YS, 2018. Correction to: Contrasting effects of engineered carbon nanotubes on plants: a review. Environ. Geochem. Health. 40:569.

Yugandhar P, Vasu AT, Chavali M, 2015. Smart materials in nanoscience and nanotechnology - An overview. VFSTR J STEM. 1:1-5.

Yuvaraj M, Subramanian KS, 2018. Development of slow release Zn fertiliser using nano zeolite as carrier. J. Plant Nutr. 3:311-20.

Zhang M, Gao B, Chen J, Li Y, Zhang M, Gao B, Chen J, Li Y, 2015. Effects of graphene on seed germination and seedling growth. J. Nanopart. Res. 17:78.

Zohary D, Hopf M, Weiss E, 2012. Domestication of plants in the old world: the origin and spread of domesticated plants in Southwest Asia, Europe, and the Mediterranean Basin. Oxford University Press, Oxford, UK. 